\title{
Voluntary false confession: An act of altruism?
}

\section{Réka Gyenis}

\section{University College Maastricht}

Supervisors: Melanie Sauerland \& Jenny Schell

Cohort: 2011

Réka Gyenis is a master student in Health and Social Psychology at Maastricht University. Her interest lies in interpersonal processes, emotional coping and contemporary therapeutic approaches in clinical psychology, notably mindfulness. Currently, she is conducting research in cooperation with the Université Catholique de Louvain, examining the relationship of failure and self-awareness in alcohol-dependent patients.

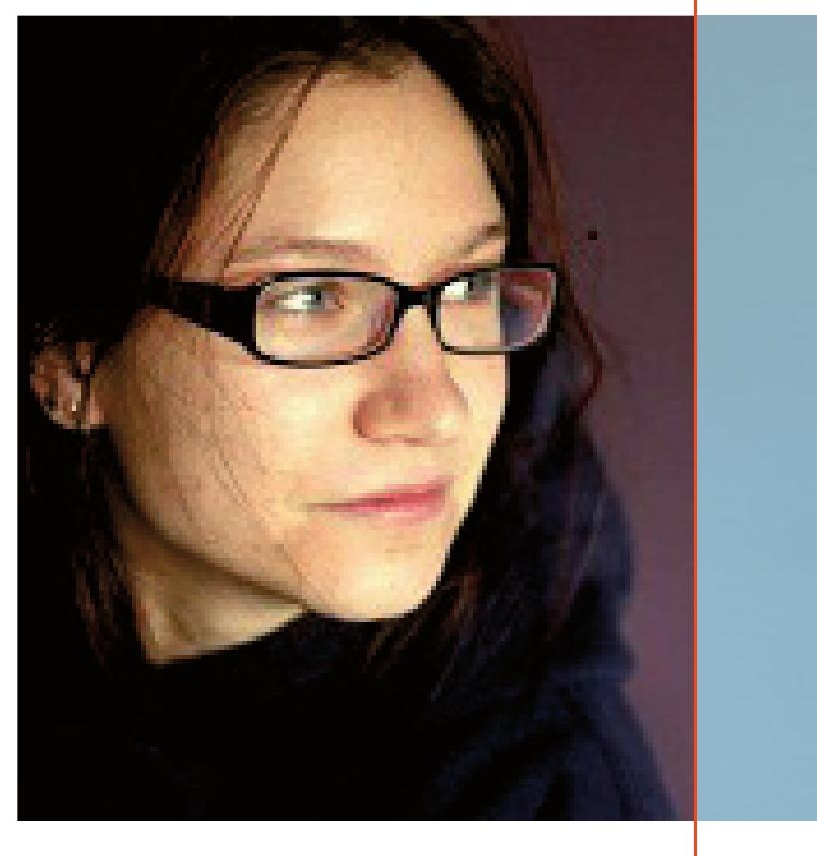


Why would innocent men choose to confess to a crime? In this article, we try to find some answers to this question. In criminal organizations, for example the Mafia, falsely confessing to hinder the work of the police seems to be an existent practice. We argue that Mafiosi have good reasons to view a police interrogation as a possibility for altruistic helping: by confessing, they sacrifice themselves to confuse the police and thus help the criminal organization. In an experimental paradigm, we tested this conceptualization: 61 university students were asked to confess to unintentional property damage. By doing so, they allegedly helped a certain faculty to get a large sum of money from an insurance company. Students who were members of this faculty confessed more often (15 out of 30) than students from other faculties (7 out of 31), even though students could not directly benefit from the insurance fraud. We argue that forces of altruistic helping are at play. The question of altruism and group-membership should be researched further in the context of false confessions and organized crime.

\section{True Story}

In 1989, magistrate Giovanni Falcone survived a murder attempt organized by the Italian mafia. The murder, however, was completed three years later, in the massacre of Via D'Amelio, where several lives were taken. After the tragic event, several suspects confessed to having participated in the crime. It soon turned out that some confessions were false, and contained misleading information about the events. This greatly hindered the work of the police, and the real perpetrators are still to be found (Bianconi, 2010; Redazioned, 2010).

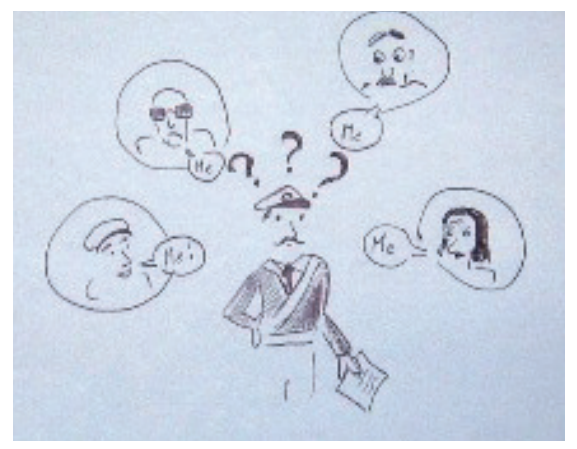

Why would an innocent man ever decide to confess to having committed something horrible? On top of that: why would he confess, if doing so will very likely make him end up in prison for many of his remaining days? Most of us would probably be confident that we would avoid such trouble at any cost. However, false confessions are an existent phenomenon in most justice systems. In what follows, we will explore voluntary false confessions and look at some reasons why innocent men may choose to confess. 


\section{What are False Confessions?}

A confession is defined as a detailed "written or oral statement in which a person admits to having committed some transgression, often acknowledging guilt for a crime" (Kassin \& Gudjonsson, 2004, p. 35). Since, in most current justice systems, a confession is treated as the ultimate proof of guilt, confessions usually entail negative consequences. A confession is false however, if there is independent evidence suggesting that the suspect is innocent (Kassin, 1997).

Kassin (1997), a renowned expert on the topic, distinguishes three types of false confessions. First, suspects may choose to confess due to external pressure from the police: They may believe that the short-term benefits of confessing (e.g., being released from a nasty interrogation situation) outweigh the long-term costs (e.g., prosecution). Therefore they confess, despite knowing that they are innocent. At other instances, it happens that innocent suspects actually start to believe in their guilt. This is a surprising but well-established psychological phenomenon: under conditions of extreme tiredness, anxiety or confusion, combined with highly suggestive interrogation techniques, the suspect may internalize guilt, and form false memories about doing things they actually have not done (Kassin, 1997). Finally, it also happens that someone just chooses to falsely confess: knowingly, and without any external pressure from the police. This third type of false confession is termed voluntary false confession.

In an attempt to gain a better idea about the prevalence of false confessions, Gudjonsson, Sigurdsson, Bragason, Einarsson, and Valdimarsdottir (2004) asked students in a survey research if they had ever been interrogated by the police, and if they had confessed. Amongst those interrogated, 59\% said that they confessed truthfully, and $4 \%$ confessed falsely. In a similar study, Gudjonsson, Sigurdsson, and Einarsson (2004) found that $1 \%$ of those interrogated while innocent confessed nevertheless. In two self-report studies (Gudjonsson \& Sigurdsson, 1994; Sigurdsson \& Gudjonsson, 1996) prisoners were asked if they had ever falsely confessed to a crime $-12 \%$ said yes. The inmates most often confessed to property offences and serious traffic violations, but false confessions to drug offence, criminal damage, violence and sexual offence also occurred.

\section{The Social Psychological Method}

It is hard to investigate how often false confessions occur in reality for a number of reasons: Often the police may never learn that the confession was false. Furthermore, we 
encounter a great secrecy surrounding the practices of organized crime, which open up to scholarly attention very rarely. We can only guess from anecdotal evidence, like the case of Via D’Amelio (Bianconi, 2010; Redazione, 2010), that this method of debilitating the legal execution is in practice.

Even though it is difficult to study this subject in reality, one may turn to alternative methods: modelling the situation in an experiment may help us better understand the reasons behind voluntary false confessions. Once we know what makes someone act this way, interrogators can pay careful attention if they encounter a suspect who could be motivated to falsely confess. This way experimental findings could contribute to a more efficient crime-persecution, keeping innocent suspects out of prison.

\section{Theory behind the Design: Why Would Anyone Falsely Confess?}

What has been found on the topic before? The existing body of empirical research is thin indeed. In self-report studies conducted amongst Icelandic prisoners (Gudjonsson \& Sigurdsson, 1994; Sigurdsson \& Gudjonsson, 1996), the most frequent reasons motioned for false confessions were: to avoid police pressure, to escape detention, and to protect somebody else. In a similar vein, according to a study interviewing college students about past false confessions to teachers and parents, $10 \%$ confessed falsely in the past, and $62 \%$ of false confessors had done so to protect someone else (Gudjonsson, Sigurdsson, Bragason et al., 2004). Helping or protecting someone else thus emerges as a possible motive for voluntary false confessions.

The empirical and anecdotal evidence suggests that choosing to falsely confess entails costs for oneself, without necessarily yielding any direct benefits. However, it is often beneficial for other parties, like the real perpetrator, or a criminal organization. Conceptualizing voluntary false confessions this way reminds us of the notion of altruism: An act is altruistic when it is intended to benefit others, not oneself, and when it is carried out even if it entails a personal sacrifice from the actor (Aronson, Wilson, \& Akert, 2007; Batson \& Powell, 2003). Whether or not people actually engage in behaviour that has absolutely no benefits for oneself (so called pure altruism) is a matter of debate. In this article we only argue that voluntary false confessions often have negative direct consequences for the suspect, while other parties often directly benefit from them. Therefore, these confessions can be considered altruistic. If this is the case, theories of altruism could help us better understand voluntary false confessions.

The question why and under what circumstances people engage in altruism is widely researched. One of the most important causes seems to be group-membership: People 
are more likely to help someone who belongs to their own group (ingroup) than someone who is seen as an outsider (outgroup; Aronson et al., 2007).

There are a number of explanations for this characteristic of altruism. According to social identity theory (Tajfel \& Turner, 1986), our identity is defined by the groups we see ourselves as members of. Our self-esteem and self-concept are influenced by the outcomes of these groups. Therefore, we want to help any ingroup-member, even if helping entails no direct benefits for ourselves. Thereby, we hope to make our group better off and thus boost our own self-esteem (Batson \& Powell, 2003). According to Social Exchange Theory (Thibaut \& Kelley, 1959), the norm of reciprocity may explain altruism. According to this norm, you are obliged to return the favor to those people who helped you in the past (Forsyth, 2010). If the person whom you help belongs to the ingroup, they are more likely to be around when you are in trouble - so one helps in order to receive benefits in the future (Brosnan \& de Waal, 2002). Finally, a more optimistic explanation of the phenomenon of altruism is given by the empathy-altruism hypothesis (Batson, 1987). The idea: feeling empathetic towards somebody can motivate us to help them, regardless of possible costs or benefits that this action entails for us.

All these mechanisms could potentially be at work behind the voluntary false confession of a mafioso. Based on accounts of mafia members (and their therapists), we can assume that a criminal organization such as the mafia highly determines its members' identity and enjoys their absolute loyalty (Lo Vers \& Lo Coco, 2004). In turn, this strongly felt membership will, through the mechanisms described above, influence when and whom one helps.

\section{Experimental Modelling}

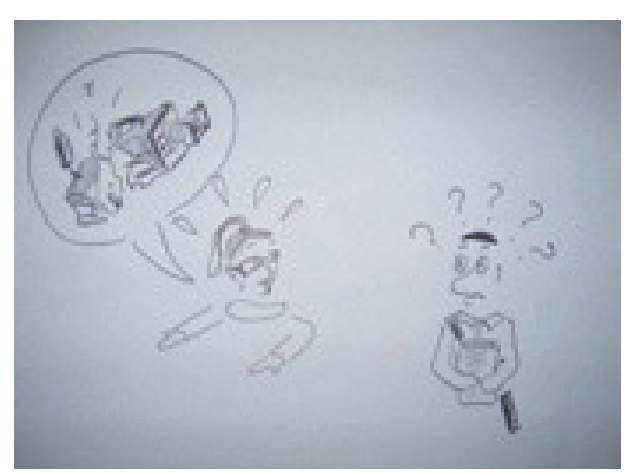

How do we test whether a voluntary false confession can be constituted as an act of altruistic helping? If this conceptualization is correct, the factor that influences altruistic helping should play a role in false confession scenarios, too. Therefore, in our experimental design (Schell, Sauerland, Leuker, \& Gyenis, 2013), we needed an ingroup, an outgroup, a crime, an innocent suspect, the opportunity to falsely confess, and beneficial value of the confession for somebody else. In such a design, we would expect more false confessions from people who are given the opportunity to help their ingroup compared to those who are given the opportunity to help an outgroup. 
To simulate group-affiliation, we picked our participants from two groups: half of the subjects (30 out of 61, 15 females) were students of University College Maastricht (UCM), a relatively small faculty of Maastricht University with students mostly dedicated to the community. The other half of the participants (31 students, 16 female) were students of Maastricht University from diverse faculties, recruited at the university library. The evidence of the "crime" was a broken film camera, supposedly very expensive, and mysteriously knocked over last night in a locked room somewhere in the university. The innocent suspects were unsuspecting students, approached one by one during their morning coffee break or during study hours, by the experimenter (one and the same female confederate throughout the whole data collection) - who they believed to be a panicky UCM student in deep trouble.

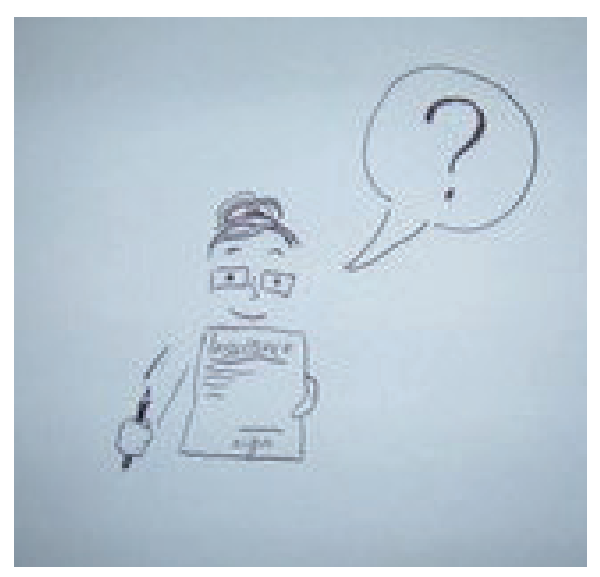

The experimenter pattered a complicated story: a movie-camera was broken last night, in a locked room. The University College research group will have to pay for this accident, which would be quite a blow - maybe they will have to stop undergraduate research! There is only one way out: there is an insurance covering the camera. However, the insurance company only pays if the damage was caused by someone (i.e. not by the wind in a locked room...) and if this person is not part of the research group (this is why the experimenter cannot volunteer to take the blame). At this point of the story, the students understood that they are asked to volunteer as a fake camera-breaker. To make the cover-story more credible, students were presented with a (fake) insurance form, which they could choose to sign, thus confessing to something they did not do, and supposedly saving a lot of money for UCM. The experimenter assured the student that they could get into absolutely no trouble. - However, students most likely knew that signing a dubious form is never safe... Then again, if a signature is all it takes to save all this money for the College, and help out a fellow student in distress - what would you do?

In line with our hypothesis, we found that UCM students were significantly more likely to confess in a scenario where the "victim" (experimenter) was from UCM, and confessing had positive consequences for UCM: $50 \%$ of UCM students (15 out of 30 ) signed the document, whereas only $23 \%$ of other UM students did (7 out of 31 ). Investigating the reasons why people confessed, empathy turned out to be the most important one: most people (19 out of $22,86 \%$ ) indicated that they confessed because they felt for the 


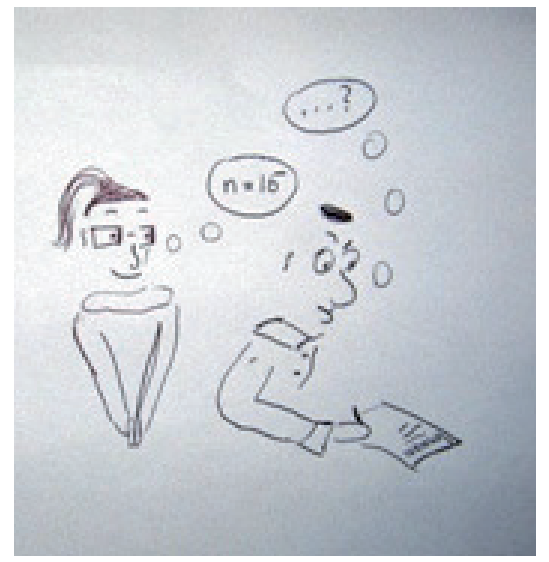

experimenter. This indicates that participants perceived the situation as one of helping and thought that there was a 'victim' in need, and they were in a position to alleviate the need: therefore they chose to confess. This finding is in line with the empathyaltruism hypothesis - participants did not help for future benefits, but acted out of simple empathy. Maybe we just saw some pure altruism in action?

\section{False Confession as an Act of Altruism?}

As opposed to past studies conducted on the subject, the present paradigm constructed the idea of false confession as a more morally equivocal act. Gudjonsson and colleagues (Gudjonsson, Sigurdsson, Bragason et al., 2004; Gudjonsson, Sigurdsson, \& Einarsson, 2004) related false confessions to deviant personality traits and a history of deviance. Misleading authorities, be it a teacher, the police or an insurance company, is usually seen as an act of deviance. In the present situation however, we put a strong moral incentive on the confession side: helping a fellow student and possibly helping one's ingroup (i.e., save UCM some money). Confessing was not seen as morally wrong by most of the participants: only 13 participants $(21 \%)$ indicated that they did not sign because they did not want to lie. Choosing to falsely confess may be seen as an antisocial, deviant, criminal act from the point of view of the justice system, but under some circumstances, it can nevertheless be seen as an altruistic sacrifice from the confessor's perspective.

\section{What Does This Have To Do with Real Criminals?}

In how far can this paradigm be taken as a model of real life? There are some limitations to experimental reality: In reality, confession usually entails foreseeable negative consequences (e.g., detention, conviction), while in our experiment, there was no predefined negative consequence. Some people thought signing entailed no risks at all, while others thought it directly led to trouble. In fact, the amount of risk subjects perceived in signing the form significantly correlated with how likely they were to actually sign it. A suspect in a criminal investigation will always know that pleading guilty will 'mean them no good'. 
Further, it may be overly optimistic to imagine a scenario of completely free choice in the police interrogation of a mafioso. Interrogation processes very often involve exerting pressure on the suspect (Kassin, 1997), so statements do not necessarily fall under Kassin's definition of voluntary. Also, we do not know what kind of rules and social norms govern the behaviour of mafia members. It might be that norms or rules exist in the organization that require members to falsely confess if interrogated, so as to further the cause of the mafia. If this were to be the case, the false confession would still qualify as 'voluntary' from the police's point of view. However, if the mafia retaliated members who fail to take the blame, a mafioso's false confession would hardly count as an act of altruism.

\section{Conclusion}

This pilot-study successfully established the notion of voluntary false confession as an act of altruism: Participants who falsely confessed clearly did so in order help the 'victim', without any immediate benefits for themselves. They did so because they empathized with the experimenter and signed the false confession despite unknown possible negative consequences for themselves. Group-affiliation was shown to be an important factor in one's decision for or against signing. This can be due to the phenomenon of positively discriminating one's ingroup, as established by Sumner in 1906.

Despite discrepancies between our design and real life, finding out what induces voluntary false confessions could be very helpful for making police investigations, like the one in the Via D'Amelio case, more effective. In the context of a close-knit criminal organization like the mafia (Lo Verso \& Lo Koko, 2004), the problem of voluntary false confessions can turn out to be a very prevalent one. 


\section{Glossary}

Internalization (in this context): Cognitive-psychological process whereby a person comes to believe that they remember some event or information. The memory however does not stem from own experience, but from misleading information presented by the police Voluntary false confession: A self-incriminating statement that is offered without external pressure from the police

Altruism: An act that entails no direct benefits for the actor, but is beneficial for others Ingroup: The collection of individuals belonging to one's own group Outgroup: Those individuals who do not belong to one's own group Empathy-Altruism Hypothesis: The idea that feeling empathetic towards somebody can motivate us to help them, regardless of possible costs or benefits that this action entails for us

Norm of Reciprocity: A norm that prescribes that you are obliged to return the favour to those people who helped you in the past 


\section{References}

Aronson, E., Wilson, T. D., \& Akert, R. M. (2010). Social psychology. (7th ed.). Upper Saddle River, NJ: Prentice Hall.

Batson, C. D. (1987). Prosocial motivation: Is it ever truly altruistic? In L. Berkowitz (Ed.), Advances in experimental social psychology. (Vol. 20, pp. 65-122). New York: Academic Press.

Batson, C. D., \& Powell, A. A. (2003). Altruism and prosocial behavior. In T. Millon \& M. J. Lerner (Eds.), Handbook of psychology: Personality and social psychology (pp. 463-484). Hoboken: Wiley.

Bianconi, G. (2010, July 21). Dai pentiti fasulli all'oscuro movente del depistaggio [From false repentants to obscure motives of sidetracking]. Corriere della Sera. Retrieved March 26, 2011 from: www.archiviostorico.corriere.it

Brosnan, S. F., \& de Waal, F. B. M. (2002). A proximate perspective on reciprocal altruism. Human Nature, 13, 129-152.

Forsyth, D. R. (2010). Group dynamics (5th ed.). Belmont, CA: Thomson Wadsworth.

Gudjonsson, G. H., \& Sigurdsson, J. F. (1994). How frequently do false confessions occur? An empirical study among prison inmates. Psychology, Crime \& Law, 1, 21-26.

Gudjonsson, G. H., Sigurdsson, J. F., Bragason, O. O., Einarsson, E., \& Valdimarsdottir, E. B. (2004). Confessions and denials and the relationship with personality. Legal and Criminological Psychology, 9, 121-133.

Gudjonsson, G. H., Sigurdsson, J. F., \& Einarsson, E. (2004). The role of personality in relation to confessions and denials. Psychology, Crime \& Law, 10, 125-135.

Kassin, S. M. (1997). The psychology of confession evidence. American Psychologist, 52, 221233.

Kassin, S. M., \& Gudjonsson, G. H. (2004). The psychology of confessions: A review of the literature and issues. Psychological Science in the Public Interest, 5, 35-67.

Lo Verso, G., \& Lo Koko, G. (2004).Working with patients involved in the mafia:Considerations from Italian psychotherapy experiences. Psychoanalytic Psychology, 21, 171-182.

Redazione (2010, July 21). Mafia e Stato: La verità coperta con depistaggi e falsi pentiti. Centronline. Retrieved March 26, 2011, from www.centronline.it

Schell, J. M., Sauerland, M., Leuker, C., \& Gyenis, R. (2013). The case of voluntary false confessions: Drivers' and students' willingness to innocently admit to traffic violations and property damage. Manuscript in preparation.

Sigurdsson, J. F., \& Gudjonsson, G. H. (1996). The psychological characteristics of 'false confessors'. A study among Icelandic prison inmates and juvenile offenders. Personality and Individual Differences, 20, 321-329. 
Sumner, W. G. (1906). Folkways. New York: Ginn.

Tajfel, H., \& Turner, J. C. (1986). The social identity theory of intergroup behaviour. In W. G. Austin \& S. Worchel (Eds.), Psychology of intergroup relations (2nd ed., pp. 7-24). Monterey, CA: Brooks/Cole.

Thibaut, J. W., \& Kelley, H. H. (1959). The social psychology of groups. New York: Wiley. 